\title{
Integrating Solar PV in Utility System Operations: Analytical Framework and Arizona Case Study
}

\author{
Jing Wu, Audun Botterud, Andrew Mills, Zhi Zhou, Bri-Mathias Hodge, Mike Heaney
}

\begin{abstract}
A systematic framework is proposed to estimate the impact on operating costs due to uncertainty and variability in renewable resources. The framework quantifies the integration costs associated with sub-hourly variability and uncertainty as well as day-ahead forecasting errors in solar photovoltaics (PV) power. A case study illustrates how changes in system operations may affect these costs for a utility in the southwestern United States (Arizona Public Service Company). We conduct an extensive sensitivity analysis under different assumptions about balancing reserves, system flexibility, fuel prices, and forecasting errors. We find that high solar PV penetrations may lead to operational challenges, particularly during low-load and high solar periods. Increased system flexibility is essential for minimizing integration costs and maintaining reliability. In a set of sensitivity cases where such flexibility is provided, in part, by flexible operations of nuclear power plants, the estimated integration costs vary between $\$ 1.0$ and $\$ 4.4 / \mathrm{MWh}-\mathrm{PV}$ for a PV penetration level of $17 \%$. The integration costs are primarily due to higher needs for hour-ahead balancing reserves to address the increased sub-hourly variability and uncertainty in the PV resource.
\end{abstract}

Keywords--Solar photovoltaic, renewable energy, operating reserves, unit commitment, system operation, integration cost.

\begin{tabular}{|ll|}
\hline \multicolumn{2}{|l|}{ Nomenclature } \\
ACE & Area control error \\
AGC & automatic generation control \\
APS & Arizona Public Service Company \\
BR & balancing reserve \\
CPS2 & Control Performance Standard 2 \\
DA & day-ahead \\
ED & economic dispatch \\
ERCOT & Electricity Reliability Council of Texas \\
HA & hour-ahead \\
ISO & independent system operator \\
MILP & mixed-integer-linear program \\
NERC & North America Electric Reliability Corporation \\
PV & photovoltaics \\
RPS & renewable portfolio standards \\
RT & real-time \\
TC & total production cost \\
UC & unit commitment \\
WECC & Western Electricity Coordinating Council \\
\hline
\end{tabular}

\section{Introduction}

Solar power is increasingly becoming an important contributor to global electricity systems, with more than 95 GW of photovoltaic (PV) power installed globally at the end of 2012 [1]. This growth in PV capacity is expected to be sustained in the United States through compliance with state Renewables Portfolio Standards (RPS) that mandate a certain percentage of electricity be produced from renewable sources. Because solar PV power output is both variable and uncertain, there are concerns about how its inclusion in system operations in significant amounts affects conventional power systems operations. Solar PV power follows a very clear diurnal cycle because of the changing position of the sun and, with no intrinsic storage capability, is not available to supply power during hours of darkness. While the expected power output during the day, assuming a clear sky, can be accurately calculated in advance, instances of clouds moving over a PV array lead to short-term variability in power output and imperfect forecasts. Large solar installations on the tens to hundreds of megawatts scale are currently being

J. Wu is with Argonne National Laboratory, Lemont, IL 60439 USA, and University of Chicago Booth School of Business, Chicago, IL 60615 USA (e-mail: jwu7@chicagobooth.edu). A. Botterud and Z. Zhou are with Argonne National Laboratory (e-mails: abotterud@anl.gov, zzhou@anl.gov), A. Mills is with Lawrence Berkeley National Laboratory (e-mail: admills@lbl.gov), B-M. Hodge and M. Heaney are with National Renewable Energy Laboratory (e-mails: Bri.Mathias.Hodge@nrel.gov, Michael.Heaney@nrel.gov). 
added to the transmission system at the same time as a large number of solar installations are being added at the distribution level, on residential and commercial rooftops. In general, aggregated distributed PV is less variable than utility-scale installations for the same capacity [2], [3]. This is because the same amount of capacity is spread over a larger geographic area, and thus localized weather conditions cannot affect as much of the installed capacity simultaneously. However, most distributed PV is "behind the meter" in that the utility is unaware of its output and sees its impact only through reduced demand. This can cause issues with the integration of distributed PV because of increased load-forecasting errors caused by the utility being unaware of the magnitude of the distributed PV generation.

To understand the impacts of this increase in solar PV power production on electricity systems, simulations of power system operations with high penetrations, or grid integration studies, are often conducted by utilities and independent system operators (ISOs). The number of grid integration studies that include solar PV power is growing [4]-[8], and solar energy is also a key technology considered in longer-term studies of future high-renewable penetration scenarios [9]-[10]. However, consideration of the complex issues surrounding sub-hourly variability and forecasting of PV power output has still been somewhat limited because of the difficulty of creating realistic sub-hourly PV datasets and forecast errors for future scenarios with increased PV production. Important parts of power system operations affected by sub-hourly variability and uncertainty include regulation reserve requirements and sub-hourly dispatch. How these operations can be changed to more economically integrate large amounts of solar PV power is an open question currently being considered by many utilities.

The contributions of this paper are to (1) propose a systematic and consistent framework to estimate integration costs for solar PV and other renewable resources, (2) quantify the integration costs and reliability implications associated with sub-hourly variability and uncertainty as well as day-ahead (DA) forecasting errors in solar PV, using the proposed framework in a case study for a utility in Arizona, and (3) show how changes in system operations may affect integration costs and propose measures for how utilities can address the challenges from solar PV and other renewable resources in a cost effective manner.

\section{Analytical Framework}

\subsection{Overview}

In order to analyze the impact of solar variability and uncertainty, we simulate the main stages in utility system operations utilizing a unit commitment (UC) and economic dispatch (ED) model of power system operations with renewable energy [11][13]. We focus on three processes that are important for the management of PV variability and uncertainty (Figure 1). First, we represent the scheduling decisions made at the DA stage as the DA commitment. Second, we represent re-commitment decisions based on updated forecast information prior to the real-time (RT) dispatch as the hour-ahead (HA) scheduling. Finally, we represent RT balancing of supply and demand based on actual sub-hourly data for renewable resources and load. The DA and HA scheduling processes are simulated with a detailed UC and ED optimization model. This model calculates a least-cost dispatch and commitment plan for the conventional generating units based on available forecasts and corresponding reserve requirements. Operating reserve requirements for the DA and HA scheduling processes are estimated to maintain sufficient reliability to meet the North American Electric Reliability Corporation (NERC) requirements during RT operations, accounting for the variability and uncertainty in solar PV, wind, and load. RT balancing is simulated using a separate minute-by-minute simulation, accounting for HA forecasting errors and the actual variability of the load, and wind and solar generation. Using these minute-by-minute deviations, we calculate the resulting Control Performance Standard (CPS2) to evaluate the impact of PV and the choice of operating reserve strategy on system reliability. The different steps of the framework are discussed in more detail below.

Fig. 1 here.

Fig. 1. Overview of Main Steps in Analytical Framework.

\subsection{Operating Reserve Requirements}

The operating reserves in the model comprise two types: contingency reserves and balancing reserves (BR). The deployment of contingency reserves to recover from unexpected events, such as the sudden loss of a large conventional power plant, is not explicitly modeled in this analysis. Instead, we require that the contingency reserve requirement must be met at all stages of system operations (DA, HA, and RT). The BR are constraints that must be met in the DA and HA scheduling and that are deployed in RT to manage minute-by-minute deviations from the HA schedule. The BR requirements for each hour are based on a set of rules that dynamically change depending on conditions. We develop the rules by examining the magnitude of 1-min deviations from the HA schedule, conditioned on either the hour of the day (in the case of load), the scheduled wind generation level (in the case of wind), or the clear sky solar production level (in the case of PV). We determine the amount of BR required in the up and down directions based on the magnitude of the 2.5th percentile and 97.5th percentile of deviations for the 
particular conditions. Our approach of establishing BR rules based on 1-min deviations from schedules is somewhat similar to the approaches used in [8] [14] [15].

We first calculate BR requirements based on the datasets from a 2004 weather year. We then apply these balancing rules to simulations using datasets from a 2005 weather year. This approach accounts for the fact that the utility will not know ahead of time what sort of deviations to expect in RT from the HA schedules, but it can use observed deviations from the previous year to determine BR requirements for the current year. The Electricity Reliability Council of Texas (ERCOT) uses a similar approach of measuring deviations of wind generation from the schedule based on a previous time period to set the regulation reserve and non-spinning reserve rules for the current time period [16].

In any particular hour we calculate the total BR as the root mean square of the individual contributions from load, wind, and PV. ${ }^{1}$ We assume that the same BR requirements apply to both HA and DA scheduling. ${ }^{2}$

\subsection{DA Commitment}

We simulate the DA commitment decisions using a UC model with unit-specific constraints. The DA decisions are based on imperfect DA forecasts of PV, wind generation, and load. The UC model is a modified version of the modeling framework presented in [11]-[13], which has been extended to consider solar PV and a more complex representation of operating reserves, based on the description above. The UC problem is a mixed-integer-linear program (MILP) problem, which is solved with CPLEX.

The objective of the optimization model is to minimize the total cost of meeting the demand for the next day. The operating costs consist of fuel costs and start-up costs for thermal generators. The model has an hourly time resolution, and the optimization is done over a 24-hr time period. Solar PV, wind, and load are represented in the UC model with their forecast values. The sub-hourly impact of PV is captured by the BR portion of the operating reserve requirements and imposed as reserve constraints in the UC model. At a high level, the objective function and the main constraints can be expressed as follows:

$$
\text { Min }(\text { total cost of day })=\sum_{t=1}^{24}\{f \text { fel costs }+ \text { penalty unserved load }+ \text { penalty unserved reserve }+ \text { startup costs }\}_{t}
$$

Subject to:

(1) Load-generation balance for all hours.

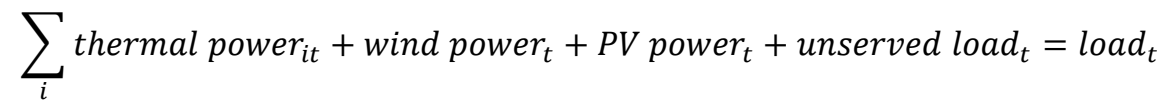

(2) PV (distributed and utility-scale) and wind dispatch for all hours.

$$
\begin{aligned}
& \text { dist } P V_{t} \leq P V \text { power }_{t} \leq \text { dist }+ \text { utility } P V_{t} \\
& 0 \leq \text { wind power }_{t} \leq \text { available wind power }
\end{aligned}
$$

(3) Spinning up/down and non-spinning reserve up requirements for all hours (with the contingency reserve only applicable to up reserves).

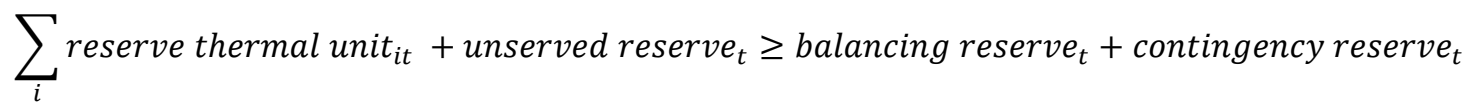

(4) Regular UC constraints for thermal plants that include minimum and maximum generation, block-wise heat rate curves, maximum ramp rates, and minimum up and down times [11]-[13], [17].

Note that the objective function contains penalties for unserved load and unmet operating reserve targets. In the case study, we set these penalties to high levels to avoid load curtailment and insufficient reserve situations because the RT dispatch simulation assumes that contingency and BR are fully met in the DA and HA scheduling.

Constraints (2) reflect the assumption that solar PV and wind generation can be curtailed, when this is the least-cost solution for the system. However, curtailment of variable generation is limited to wind and utility-scale PV installations, because we assume that system operators have no ability to control or communicate with customer-sited distributed PV.

In constraints (3), the operating reserves are split into spinning and non-spinning reserves, and are a function of the

\footnotetext{
${ }^{1}$ The use of the root mean square of the load and wind and PV contributions is based on the assumption that deviations are independent.

${ }^{2}$ This implies that the BR used in the HA will be known for the same hour during the DA commitment. This is not an issue for the BR needed for load and PV because it depends on the hour of the day and the clear sky solar production (which are both known a day ahead). However, it is a simplification for wind because the reserve requirements are contingent on the HA wind schedule, which are unknown at the DA stage.
} 
contingency and BR requirements.

The scheduling model builds on several simplifying assumptions. The load is considered inflexible and does not respond to prices. This is a conservative assumption, since it is likely that in a future scenario with a smarter grid the demand-side would become more flexible and capable of responding to price signals. The model also assumes that all operating reserves have to be provided by thermal units, and does not consider provision of reserves from flexible demand resources, energy storage, or renewables. In the future, such resource may contribute towards system flexibility and operating reserves and thereby reduce the cost of integrating renewable energy into the system. ${ }^{3}$ Another limitation is that transmission constraints in the utility system are not represented. ${ }^{4}$ Moreover, we assume that the utility uses its own generation to meet its loads and does not trade with other suppliers. This tends to overstate the challenges and costs with integrating PV into the system, as market purchases and exchanges of power with neighboring regions will likely increase the access to flexible resources.

For a complete mathematical description of the UC model, we refer to [18] (appendix C).

\subsection{HA Scheduling}

After the DA commitment decisions are made, we assume that the utility will update its schedule in the HA time frame based on the updated HA forecasts of PV, wind, and load. The HA forecast is generally more accurate than the DA forecast. The HA schedule makes adjustments in the commitment decisions for peaking units as needed. We use the same optimization model as in the DA stage to re-commit the quick-start units (i.e. combustion turbines) at the HA stage, keeping the commit of other units fixed from the DA stage. ${ }^{5}$ The final HA schedules will end up being more costly than they would have been if load, wind, and PV forecasts were the same at the DA stage as at the HA stage. The higher costs are due to HA decisions that include redispatching generation, turning on quick-start units that would have otherwise not been needed, or in extreme cases not meeting reserve requirements.

\subsection{RT Dispatch}

We developed a Python program to simulate the minute-by-minute RT operation. The program deploys the BR held at the HA stage to meet minute-by-minute deviations from the HA schedules (Figure 2). The deployment of the BR is constrained by the total available BR capacity in the up or down direction and by the rate at which BR can be fully deployed, assumed to be 10 min. Furthermore, a 5-min moving average filter is applied to the 1-min deviations to set the deployment of BR because it is not necessary to chase every deviation to maintain compliance with the NERC CPS2 standard. We assume that a combination of instructions from the RT schedulers and automatic generation control (AGC) would be able to provide the deployment of BR.

Any minute-by-minute deviation from the HA schedules that is not met by deployment of BR leads to a non-zero area control error (ACE). The resulting CPS2 score is calculated by examining the number of 10-min periods in which the average ACE over the 10-min period remains within a utility-specific minimum threshold called $\mathrm{L}_{10}[19]$. Hence, the estimated CPS2 score is an outcome of the simulated deployment of the available BR.

Fig. 2 here.

Fig. 2. Illustration of Method Used To Simulate Deployment of BR in Real Time

\subsection{Estimate of Integration Cost}

There is no single accepted definition of the term "integration costs" and no generally agreed-upon way to correctly calculate such costs [20]. We propose a very specific definition of this cost, which is useful for understanding the magnitude of the costs that would be ignored if PV generation was assumed to be perfectly forecasted in the DA and to not increase the BR requirements in the HA scheduling. Hence, to estimate the integration cost, we run three simulations and calculate the resulting total production cost (TC) for each case as follows:

$\boldsymbol{T} \boldsymbol{C}_{\boldsymbol{P}}$ is the total production cost for a case in which PV is perfectly forecasted at the DA stage and does not increase BR requirements for the HA scheduling.

$\boldsymbol{T C}_{\boldsymbol{H A}}$ is the total cost for a case in which the BR requirements are increased to accommodate PV for the HA scheduling, still under the assumption that the DA commitment is based on a perfect DA forecast.

$\boldsymbol{T C}_{\boldsymbol{D A}}$ is the total cost for a case with both increased BR requirements for the HA scheduling and imperfect DA forecasts.

We estimate the integration costs and its two sub-components, all in \$/MWh-PV, as follows:

\footnotetext{
${ }^{3}$ In the case study, we run several sensitivity cases with the assumption that nuclear units have the flexibility to provide reserves. This assumption deviates

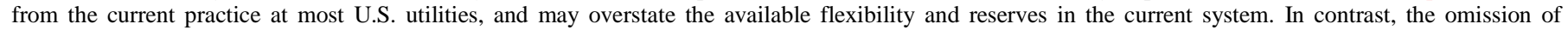
operating reserves from demand response, energy storage, and renewable energy resource may understate the level of flexibility in the future system.

${ }^{4}$ The utility we analyze in the case study expects to build sufficient transmission to eliminate most internal bottlenecks in their transmission system.

${ }^{5}$ This is also a somewhat conservative assumption relative to current practices at APS, because the RT operators are constantly monitoring the need for units to be started or stopped within the operating day, well before the actual operating hour.
} 
Cost of the BR in the HA scheduling, $I C_{b r}$ :

Cost of DA forecast uncertainty, $I C_{f c s t}$.

$$
I C_{b r}=\left(T C_{H A}-T C_{P}\right) /(\text { Available } P V \text { generation }) \text {. }
$$

$$
I C_{f c s t}=\left(T C_{D A}-T C_{H A}\right) /(\text { Available } P V \text { generation })
$$

Total integration cost, $I C_{t o t}$ :

$$
I C_{t o t}=I C_{b r}+I C_{f c s t}
$$

Note that our definition of integration costs include changes to the operational costs only, i.e. it does not consider possible changes to the longer term capital costs which may arise as a higher share of renewable energy changes the overall portfolio of generating resources in a system. Alternative definitions of integration costs, which also attempt to capture longer-tem effects including reduced utilization of the existing generators, are provided in [21] [22].

\section{Data}

We use the proposed framework to analyze solar PV integration for Arizona Public Service Company (APS). APS is the largest utility in the state of Arizona. APS serves more than 1.1 million customers covering a service territory of almost 35,000 square miles. As a vertically integrated utility, APS has more than 8,600 MW of generation, 5,300 miles of transmission lines, and 28,000 miles of distribution lines. APS has excellent solar resources located within its service territory and is expecting a large increase in solar PV installations in the near future.

We analyze the impact of distributed and utility-scale PV on the APS system based on projected conventional generation, load, and wind and PV resources in 2027. We develop two scenarios (described in Table 1): one using the base case (low PV) and the other using the expanded renewables case (high PV) from the 2012 APS Integrated Resource Plan [23]. The low-PV case includes sufficient PV to meet $8.8 \%$ of the annual energy, and the high-PV case includes enough PV to meet $17.0 \%$ of the annual energy (prior to any curtailment of renewables). Both cases also consider wind penetration of $4.9 \%$ of annual energy.

TABLE 1

MAIN SCENARIOS USED TO EVALUATE THE IMPACTS OF PV (2027)

\section{Table 1 here.}

We maintain synchronized relationships between hourly load, wind, and PV by using historical data from the same weather year (2005). The corresponding datasets consists of time series where we synthesize sub-hourly data at a 1-min resolution, representing actual realizations. We also develop hourly DA and HA forecasts for load, wind, and PV. The datasets, described in more detail below, rely heavily on wind and solar profiles developed as part of [4][24] with selected locations chosen to model expected installations within the APS service territory.

\subsection{Load}

To estimate the 2027 load, we scaled the historical hourly load from APS by a constant scaling factor of 1.384 to match the projected annual demand from [4]. We had access to DA and HA load forecast errors recorded by APS in 2010 and created DA and HA load schedules for 2027 by assuming that the historical DA and HA forecast errors from 2010 would occur with the same magnitude and on the same hour of the year in 2027. Figure 3 shows the resulting hourly HA load schedule for 2027.

Historical load data with 1-min resolution for a limited time period (44 days in 2007) was used to derive a time series with 1 min variability for realized load, as further explained in [18].

\section{Fig. 3 here.}

Fig. 3. Estimated HA Load Schedule for 2027, Chronological and Sorted in Descending Order (Load Duration Curve)

\subsection{Wind}

The wind data used in this analysis are based on wind data and DA forecasts developed for [24]. The existing wind farms were approximated by 9 30-MW sites (270-MW nameplate capacity), and the new wind sites were approximated by 12 additional 30-MW sites (360-MW nameplate capacity). The DA schedules generated in [24] were scaled by a factor of 0.9 to remove the DA wind forecast bias in the original dataset.

HA schedules for wind were created based on the 1-min actual wind output recorded 30 min prior to the start of the operating hour. The HA forecast for wind was therefore based on an assumption of a 30-min persistence of wind. 
The 1-min time series of actual wind outputs was created by interpolating between the 10-min average wind outputs from the original dataset [24] using a cubic spline fit.

\subsection{Solar $P V$}

PV was modeled as a mixture of different PV configurations (e.g., tracking or fixed, horizontal or tilted) and a combination of distributed and utility scale. In all cases, DA schedules were based on hourly DA insolation forecasts developed in [24] and then run through the PVWatts program [25] to estimate DA schedules for PV. PVWatts converts insolation into PV production based on the PV plant capacity, PV plant configuration, an assumed DC-to-AC derate factor (assumed to be 0.83 in this case), and ambient temperature. Ambient temperature for a nearby weather station (depending on the location of the modeled PV site) in the same weather year (2005) was used in PVWatts to generate PV generation data.

HA schedules were based on assuming that the 1-min clear sky index 30 min prior to the start of the operating hour would be the clear sky index for the operating hour, where the clear sky index is defined as the ratio of the actual PV generation to the clear sky PV generation. The HA forecast of PV therefore corresponds to a 30-min persistence-of-cloudiness forecast. ${ }^{6}$

1-min solar data were synthesized by using an approach that starts with hourly satellite-derived solar data for each site and then adds sub-hourly variability. The method of synthesizing sub-hourly variability accounts for the correlation of variability between sites on sub-hourly time scales and the amount of sub-hourly variability that would be expected for a particular level of cloudiness.

\subsection{Forecasting Errors}

DA forecasting errors affect the degree to which resources need to be re-dispatched or committed in the HA scheduling and HA forecasting errors contribute to the need for and deployment of BR in RT. Not surprisingly, load, wind, and PV forecast errors are all consistently larger in DA scheduling than in HA scheduling (Table 2). When normalized to peak load or nameplate capacity and averaged across all hours of the analysis period, load has lower forecast error than both wind and PV, and PV has considerably lower forecast error than wind (Table 2).

TABLE 2

NORMALIZED FORECASTING ERROR STATISTICS FOR LOAD, WIND, AND SOLAR PV FOR DA (UPPER) AND HA (LOWER) (2027)

Table 2 here.

\subsection{Conventional Generation}

We derived the data characteristics of the thermal generators in the system based on [23] and [26]. The current generator portfolio, as well as the generation expansion and retirement plans until the year 2027 is described in [23]. [26] provides estimates of several generator parameters, such as capacities, unit blocks, and heat rates. Each unit is modeled with a minimum block and three equally sized dispatch blocks between minimum generation and full output. Fuel price assumptions for 2027 are based on projections in [27].

The projected conventional resource in 2027 includes 67 generation units. Eight units are partly owned by the company (i.e. the three nuclear units and five coal units), and we reduced the capacity, ramp rates, start-up costs, and other relevant parameters according to the ownership percentage. Based on existing practices at APS five of the eight coal plants are treated as must-run units that can dispatch between minimum and maximum generation, but they cannot be turned off. Similarly, the default assumption is that nuclear units are always operated at full nameplate capacity, although we also investigate the impacts of a more flexible operating scheme for nuclear generators, as discussed below. Table 3 shows the conventional resource capacity contribution and the fuel prices used in our study. For the given fuel price assumptions, nuclear is the technology with the lowest operating costs, followed by coal, different types of gas-fired generation, and finally the two oil units. For a more detailed overview of the data used in the case study we refer to [18].

TABLE 3

Generator Capacity and Fuel Price by Technology (ST-Steam, CC-Combined Cycle, CT-Combustion Turbine)

Table 3 here.

\footnotetext{
${ }^{6}$ The use of HA persistence forecasts for solar and wind is a conservative assumption which does not consider more advanced forecasting techniques.
} 


\section{Results}

\subsection{Impact of PV on Grid Operations}

Our simulation results indicate that the combination of must-run generation, inflexible nuclear operations, no trading with neighbors, and large amounts of solar in the high-PV case leads to very high levels of renewable curtailment during low-load and high solar periods. For a high-PV case to be practical, some solution to these challenges will be necessary. We included a "flexible nuclear" case as one option for introducing flexibility during low-load and high solar periods. ${ }^{7}$ The impacts of PV deployment under the assumption of constant nuclear operation in the low-PV and high-PV cases and the alternative flexible nuclear operation in the high-PV case are summarized in Table 4.

The addition of PV increases the variability and uncertainty between HA scheduling and RT operations, and this is managed through additional BR, as explained in Section 2.2. The peak and average requirement for BR in the up direction without PV, with low PV, and with high PV are shown in Table 4, along with the estimated PV integration costs. The total integration cost is primarily due to the cost of holding additional BR during HA scheduling (balancing reserve cost). The remaining portion of the integration costs (DA forecast error cost) is from re-dispatch of online generation, changes in UC within the operating day for peaking units, and imperfect UC decisions for other units due to DA forecasting errors.

The assumption of flexible nuclear operation in the high-PV flexible nuclear case (where all the nuclear units can operate below maximum output and also provide up and down reserves) decreases the integration cost from 3.77 to $1.74 \$ / M W h-P V$ and greatly reduces the need to curtail renewables from almost $18 \%$ down to $3.4 \%$ of available renewables (Table 4).

On the basis of the RT simulations of minute-by-minute deviations from the HA schedule, we find that the BR based on the 2.5th to 97.5th percentile of deviations are sufficient to achieve a CPS2 score that exceeds NERC minimum standards of a CPS2 score of $90 \%$ (Table 4), though none of the cases achieve APS's current practice of aiming to maintain a 99\% CPS2 score. The decrease in the CPS2 score, particularly in the high-PV scenario, indicates there is a significant degradation of CPS2 performance when BR requirements are based on the 2.5th to 97.5th percentile of HA schedule deviations, an issue we address through sensitivity studies discussed in the next section.

TABLE 4

IMPACT OF PV IN 2027 USING BASE ASSUMPTIONS

Table 4 here.

\subsection{Sensitivity Cases with High PV}

We conduct an extensive sensitivity analysis of system cost and reliability (CPS2 score), using the high-PV (Flex. Nucl.) scenario as a benchmark. We vary assumptions about BR, system flexibility, fuel prices, and forecasting errors, as shown in Table 5. For these sensitivities we find that integration costs vary within the range of $\$ 1.0$ to $\$ 4.4 / \mathrm{MWh}-\mathrm{PV}$ (Figure 4). The majority of the integration cost is due to an increase in the cost of BR held during HA scheduling, whereas DA forecast errors continue to be a smaller contributor. Figure 4 shows that changes in fuel prices and forecast assumptions for wind and load do have an effect on integration costs, but the impacts are less pronounced compared to those for the other sensitivities, which are discussed in more detail below. We also find that the renewables curtailment varies with the sensitivity cases between $0.9 \%$ and $9.1 \%$ of the renewable potential.

In the sensitivities related to BR, we examine two options for increasing the CPS2 performance with high PV penetration: (1) increase the amount of BR held in the HA or (2) increase the maximum rate of deployment (change from our initial assumption of full deployment in $10 \mathrm{~min}$ to full deployment in $5 \mathrm{~min}$ ). Either option increases the CPS2 score to more than 95\%, but both also increase the integration costs. There is clearly a trade-off between integration costs and the utility's CPS2 performance (Figure 5); the proper balance between the two will depend on the priorities of the utility.

TABLE 5

OvERVIEW OF SENSITIVITY CASES FOR High-PV (FLEX. NUCL.) 2027 SCENARIO

\section{Table 5 here.}

The sensitivities related to flexibility show that system flexibility is essential for minimizing integration costs. In addition to the comparison of constant and flexible nuclear operations with high PV mentioned earlier, we show the impact of reduced system flexibility by reduced ramping rates for thermal generators, which give a slight increase in the integration cost (Figure 5).

\footnotetext{
${ }^{7}$ Although flexible nuclear operation is not common practice at APS or other U.S. utilities, nuclear plants are operated in a flexible manner in France and Germany [28].
} 
Moreover, curtailment of renewable generation can be reduced to less than $1 \%$ by artificially introducing a large penalty for such curtailments in the UC/ED model (min RE curtailment case). The results show that following such a strategy that minimizes renewable curtailment changes the dispatch of thermal units and therefore results in a significant increase in the integration cost, from $\$ 1.74 / \mathrm{MWh}-\mathrm{PV}$ in the high-PV (Flex. Nuclear) case to $\$ 2.14 / \mathrm{MWh}-\mathrm{PV}$ (Figure 4). Hence, reducing curtailment of renewables comes at a significant cost.

To further highlight the importance of flexibility, we constructed a worst-case scenario in which limits to flexibility (including constant nuclear output, low ramp rates for other thermal generators, and penalties on renewables curtailment) and increased BR requirements were simultaneously assumed. In this case, the integration cost increases to $\$ 9.6 / \mathrm{MWh}$ and renewables curtailment exceeds $10 \%$ of available renewable generation (despite the penalties for renewable curtailment), and it also becomes challenging to meet the BR requirements with frequent occurrences of reserve shortfalls. This highlights the importance of finding buyers for excess power during times with high PV production or the need to increase flexibility from existing thermal power plants or other resources (e.g. demand response or energy storage). For a more comprehensive set of case study results and corresponding analysis we refer to [18].

Fig. 4 here.

Fig. 4. PV Integration Cost Estimates for Sensitivity Cases Using the High-PV (2027) Scenario with Flexible Nuclear Operations as a Benchmark

Fig. 5 here.

Fig. 5. Tradeoff between Balancing Performance (CPS2 Score for Net Load) and Integration Cost of PV

\subsection{Comparison to Other Integration Studies}

It is difficult to compare the findings presented above directly to the results from other integration studies, since various definitions of renewable energy integration costs exist [20], and the modeling assumptions and methodologies also vary. Moreover, there are relatively few studies of solar PV integration so far. However, below we present a brief comparison to other relevant studies.

A recent study of PV integration into the APS system is documented in [6]. BR requirements were calculated for three different CPS2 levels (90, 95, and 99\%) and two different PV levels: 1038MW in 2020 and 1669MW in 2030. The latter PV penetration is similar to the low PV case in our analysis. Solar PV integration costs in the ranges of \$1.53-2.08/MWh-PV and \$2.43-3.04/MWh-PV were found for 2020 and 2030, respectively. The estimated 2030 integration costs in [6] are somewhat higher than in the low PV case in our study. This may have to do with different approaches to estimating the need for BR: the approach in [6] was to calculate fixed BR levels for each month, whereas we estimated BR needs dynamically for each individual hour of the year. There are also several differences in terms of modeling assumptions and data. For instance, we considered the impact of both DA and HA forecasting errors directly in our study (Fig. 1), where the study in [6] only considered increased BR due to HA forecasting errors. In another integration study from Nevada [8], PV integration costs were estimated to be between \$3/MWh-PV and \$8/MWh-PV, for PV penetration levels between $1 \%$ and $15 \%$ of the system load. Increased need for BR was identified as the main driver of integration costs, as it forces thermal generators to operate at lower efficiency (higher heat rates). A recent study from Europe [22] uses a wider definition of PV integration cost, accounting for capacity cost (defined as the increase in cost per MWh output of incumbent generation as they need to operate with a lower load factor), transmission cost, balancing cost, and distribution network cost. Total integration costs were estimated for PV penetration levels between $2 \%$ and $18 \%$ for 11 countries in Europe, with a wide range of results, from a negative $€-50 / \mathrm{MWh}-\mathrm{PV}$ to $€ 26 / \mathrm{MWh}-\mathrm{PV}$, with the majority in the $€ 10-20 / \mathrm{MWh}-\mathrm{PV}$ range. It was found that countries in the south (like Greece) have much lower integration costs (i.e., actually negative under penetration levels below 12\%) than countries in the north, due to better alignment between the solar PV resource and peak load. Moreover, the so called capacity cost was the main driver for total PV integration costs, whereas balancing costs due to increased BR only lead to modest cost increases in the $€ 0.5-1.0 / \mathrm{MWh}$ PV range.

There is a more extensive literature of wind integration studies and costs. A summary of estimated wind integration costs from studies in Europe and the United States is provided in [29]. For wind penetrations up to $20 \%$ of load increases in system operating costs arising from wind variability and uncertainty amounted to €1.0-4.5/MWh-wind.

\section{Conclusion and Future Work}

Utilities can manage variability and forecast uncertainty of PV through several sources of flexibility available in existing operating practices. These practices include re-dispatch of committed generation units, commitment of peaking units within the operating day, and holding additional resources in reserve during hour-ahead scheduling to be deployed in real-time. Our results 
show that managing variability and uncertainty through these methods is not without cost, but at the same time the magnitude of the cost depends on a number of factors and particularly on the level of flexibility in the system.

In the United States, an important criterion for managing increased amounts of PV is to maintain reliability as measured by NERC balancing standards. Our analytical framework develops hourly balancing reserve requirements based on statistical analysis that can be used by utilities in the hour-ahead scheduling process to ensure that sufficient resources are available within the operating hour to manage deviations from the hour-ahead schedule. The case study results show that increased variability and uncertainty from PV lead to an increase in these hour-ahead up and down balancing reserve requirements, particularly under the high-PV assumption.

In the low-PV scenario we find that the operational challenges are relatively modest. In the high-PV scenario, however, the challenges are more substantial, with curtailments of renewable energy reaching a very high level $(17.8 \%$ of the total potential energy) while it also becomes challenging to meet the increased balancing reserve requirements in a few hours of the year. However, we find that with flexible nuclear plants providing both energy and reserves the integration cost drops substantially. Flexible nuclear dispatch also reduces the curtailment of renewables to $3.4 \%$ of the total resource, indicating that the increased system flexibility makes it much easier to absorb high solar PV penetration levels.

Sensitivity analysis with the high-PV assumption illustrates that utility's ability to balance the system can be improved either by increasing the balancing reserve or by requesting that they respond faster. However, this comes at the expense of higher integration costs and also more curtailment of renewable energy. Minimizing the level of renewable curtailment also increases the integration cost. Hence, we conclude that some economic curtailment of renewables during challenging periods make sense from a cost perspective. Across all the sensitivity cases the primary contributor to the integration cost is the increase in balancing reserve due to short-term variability and forecast uncertainty, whereas the cost from day-ahead forecast errors plays a less significant role.

The case study does have a number of limitations. An important limitation is that we did not model exchange with the broader Western Electricity Coordinating Council (WECC) area outside of the utility boundaries, an assumption that is likely to overstate the challenges with low-net-load periods, particularly if neighboring utilities are adding less renewables to their systems. Moreover, the analytical framework does not fully reflect the flexibility to make recommitment decisions at any time between day-ahead and hour-ahead scheduling. On the other hand, the revised dispatch and commitments in the hour-ahead were made with a single run of the optimization model over a 24 -hr period based on the assumption that the hour-ahead forecasts are known for the entire day.

Finally, we only investigated a small subset of the potential future sources of system flexibility in this study. Additional sources include demand side programs that shift load into low net-load periods or energy storage. Another important source of flexibility is the potential provision of reserves from wind and utility-scale solar resources. As long as the utility can send a control signal to these resources they can provide operating reserves, particularly in the down direction. In future work, we therefore recommend exploring these additional sources of system flexibility. Potential benefits of stochastic scheduling for system cost and reliability is also an area we want to explore in future work. Finally, investigation of the consequences of using other metrics for reliability (instead of CPS2) and integration costs (e.g. that include capital cost implications) also represent interesting directions for future research.

\section{Acknowledgment}

This work was supported by the U.S. Department of Energy SunShot Initiative. The submitted manuscript has been created by UChicago Argonne, LLC, Operator of Argonne National Laboratory (“Argonne”). Argonne, a U.S. Department of Energy Office of Science laboratory, is operated under Contract No. DE-AC02-06CH11357.

\section{References}

[1] IEA (International Energy Agency), PVPS Report A Snapshot of Global PV 1992-2012, Report IEA-PVPS T1-22:2013. [Online]. Available: http://www.iea-pvps.org

[2] Marcos, J., L. Marroyo, E. Lorenzo, D. Alvira, and E. Izco, "From Irradiance to Output Power Fluctuations: The PV Plant as a Low Pass Filter," Progress in Photovoltaics: Research and Applications 19(5):505-510, 2011. doi:10.1002/pip.1063.

[3] Mills, A., and R. Wiser, "Implications of Wide-Area Geographic Diversity for Short-Term Variability of Solar Power," Report LBNL-3884E, Lawrence Berkeley National Laboratory, Berkeley, CA, 2010. [http://eetd.lbl.gov/ea/emp/reports/lbnl-3884e.pdf].

[4] General Electric (GE), Western Wind and Solar Integration Study, 2010.

[5] Ma, J., Y. Makarov, C. Loutan, and Z. Xie, "Impact of Wind and Solar Generation on the California ISO's Intra-hour Balancing Needs," Proc. IEEE Power \& Energy Society General Meeting, Detroit, MI, 2011.

[6] Black \& Veatch, "Integrated Photovoltaic (PV) Integration Cost Study," prepared for Arizona Public Service Company, Nov 2012.

[7] California Independent System Operator (CAISO), "Integration of Renewable Resources at $20 \%$ RPS," CAISO 2010. [http://www.caiso.com/2804/2804d036401f0.pdf]

[8] Navigant Consulting, Sandia National Laboratories, Pacific Northwest National Laboratories, and NV Energy, "Large-scale Solar Integration Study," 2011. [http://www.navigant.com/insights/library/energy/large-scale_pv_integration_study/].

[9] Eichman J.D, Mueller F., Tarroja B., Smith Schell L., Samuelson S., "Exploration of the integration of renewable resources into California's electric system using the Holistic Grid Resource Integration and Deployment (HiGRID) tool," Energy 50: 353-363, 2013.

[10] Mai T., Mulcahy D., Hand M.M., Baldwin S.F., "Envisioning a renewable electricity future for the United States," Energy 65: 374-386, 2014. 
[11] Wang J., A. Botterud, R. Bessa, H. Keko, L. Carvalho, D. Issicaba, J. Sumaili, and V. Miranda, "Wind Power Forecasting Uncertainty and Unit Commitment," Applied Energy 88(11): 4014-4023, 2011.

[12] Zhou Z., A. Botterud, J. Wang, R.J. Bessa, H. Keko, J. Sumaili, and V. Miranda, "Application of Probabilistic Wind Power Forecasting in Electricity Markets," Wind Energy 16(3):321-338, 2013.

[13] Botterud, A., Z. Zhou, J. Wang, J. Sumaili, H. Keko, J. Mendes, R.J. Bessa, and V. Miranda, "Demand Dispatch and Probabilistic Wind Power Forecasting in Unit Commitment and Economic Dispatch: A Case Study of Illinois," IEEE Transactions on Sustainable Energy 4(1):250-261, 2013.

[14] Charles River Associates (CRA), 2010, "SPP WITF Wind Integration Study," 2010. [http://www.spp.org/publications/2010.zip].

[15] Makarov, Y. V, C. Loutan, J. Ma, and P. de Mello, “Operational Impacts of Wind Generation on California Power Systems," IEEE Transactions on Power Systems 24(2):1039-1050, 2009.

[16] Electricity Reliability Council of Texas (ERCOT), "2011-2012 ERCOT Methodologies for Determining Ancillary Service Requirements," 2011.

[17] Rajan D, Takriti S., "Minimum up/down polytopes of the unit commitment problem with start-up costs," Report RC23628, IBM Research, June. 2005

[18] A. Mills, A. Botterud, J. Wu, Z. Zhou, B-M. Hodge, M. Heaney, "Integrating Solar PV in Utility System Operations," Report ANL/DIS-13/18, Argonne National Laboratory, Oct. 2013.

[19] Jaleeli, N., and L. S VanSlyck. "NERC's New Control Performance Standards," IEEE Transactions on Power Systems 14 (3): $1092-99$, 1999. doi:10.1109/59.780932.

[20] Milligan, M., E. Ela, B. Hodge, B. Kirby, D. Lew, C. Clark, J. DeCesaro, and K. Lynn, "Integration of Variable Generation, Cost-Causation, and Integration Costs," The Electricity Journal 24(9):51-63, 2011.

[21] Hirth L, F. Ueckerdt, O. Edenhofer, "Integration costs revisited - An economic framework for wind and solar variability," Renewable Energy 74: 925-939, 2015.

[22] Pudjianto D., P. Djapic, J. Dragovic, G. Strbac, "Grid Integration Cost of PhotoVoltaic Power Generation: Direct Costs Analysis related to Grid Impacts of Photovoltaics," Technical Report, Imperial College, United Kingdom, Sept. 2013.

[23] Arizona Public Service, 2012 Integrated Resource Plan, March 2012. [ http://www.aps.com/library/resource\%20alt/2012ResourcePlan.pdf]

[24] Potter, C., D. Lew, J. McCaa, S. Cheng, S. Eichelberger, and E. Grimit, "Creating the Dataset for the Western Wind and Solar Integration Study," Wind Engineering 32:325-338, 2008.

[25] System Advisor Model Version 2013.1.15 (SAM 2013.1.15). National Renewable Energy Laboratory. Golden, CO. [https://sam.nrel.gov/content/downloads]

[26] Ventyx, Ventyx Electric Power Industry Database, 2012. [https://velocitysuite.ventyx.com/].

[27] EIA (U.S. Energy Information Administration), “Annual Energy Outlook 2012,” 2012 [http://www.eia.gov/].

[28] OECD/Nuclear Energy Agency, "Nuclear Energy and Renewables: System Effects in Low-carbon Electricity Systems," Paris: OECD Publishing, 2012. [http://dx.doi.org/10.1787/9789264188617-en].

[29] H. Holttinen, et al., "Design and operation of power systems with large amounts of wind power: Final summary report, IEA WIND Task 25, Phase two 2009-2011,” Technical Report VTT TECHNOLOGY 75, VTT Technical Research Centre of Finland, 2013. 


\section{Figures:}

Fig. 1:

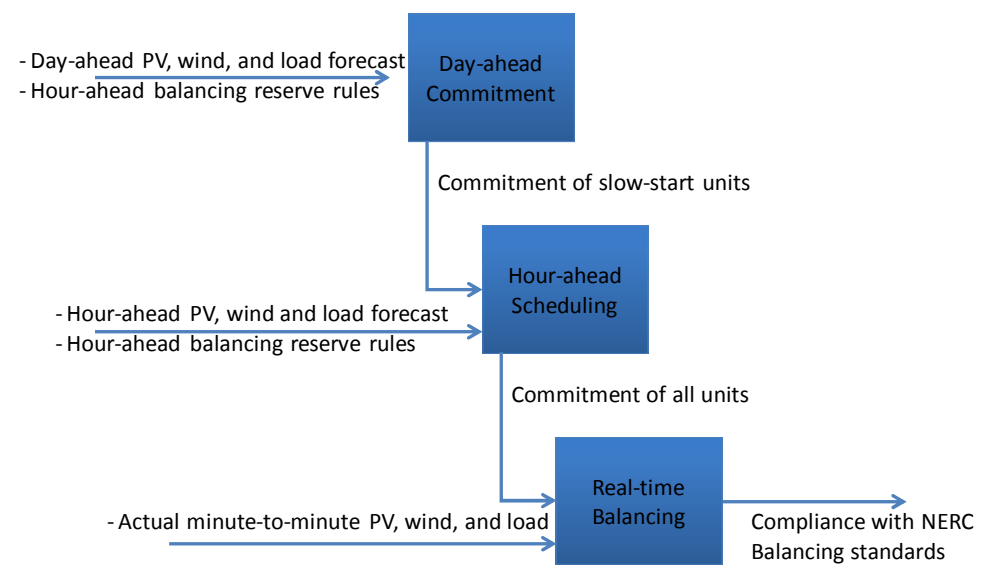

Fig. 1. Overview of Main Steps in Analytical Framework.

Fig. 2:

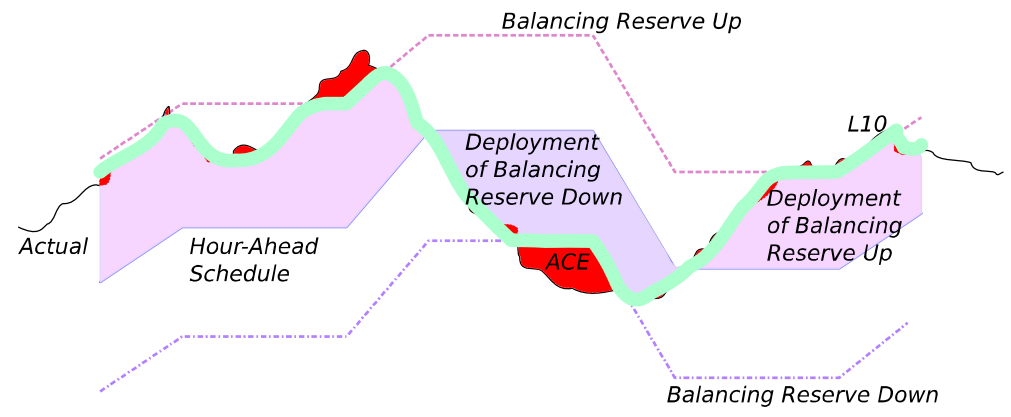

Fig. 2. Illustration of Method Used To Simulate Deployment of BR in Real Time

Fig. 3:

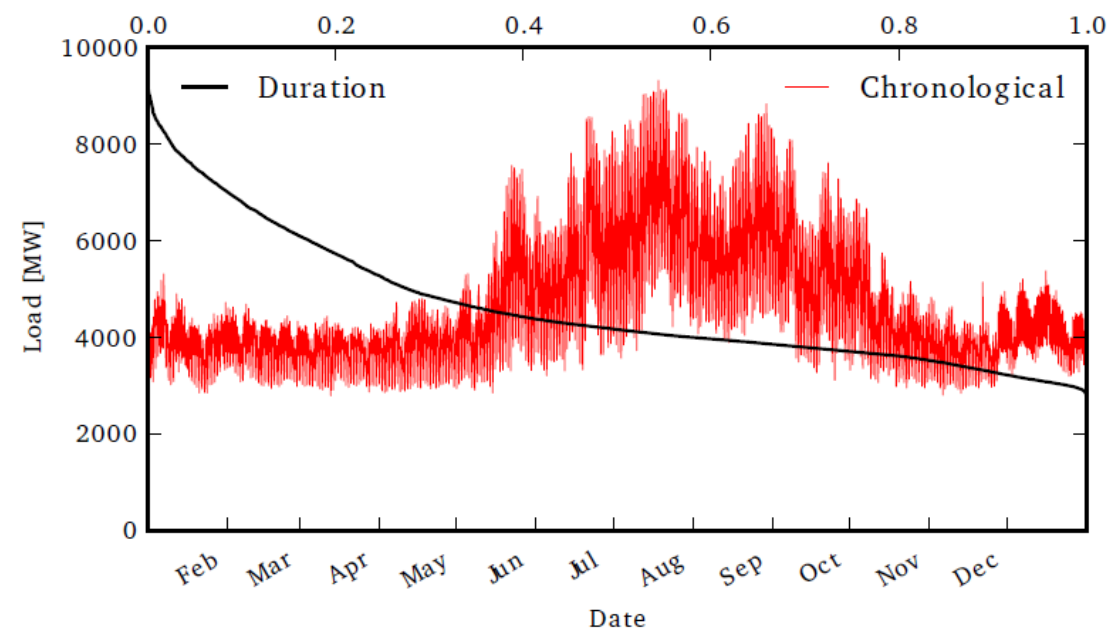

Fig. 3. Estimated HA Load Schedule for 2027, Chronological and Sorted in Descending Order (Load Duration Curve) 
Fig. 4:

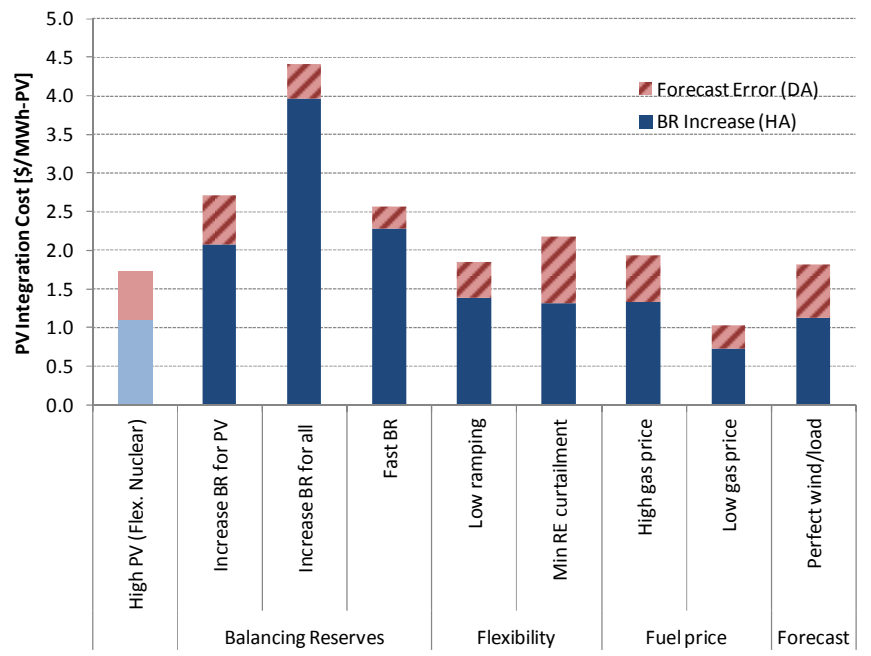

Fig. 4. PV Integration Cost Estimates for Sensitivity Cases Using the High-PV (2027) Scenario with Flexible Nuclear Operations as a Benchmark

Fig. 5:

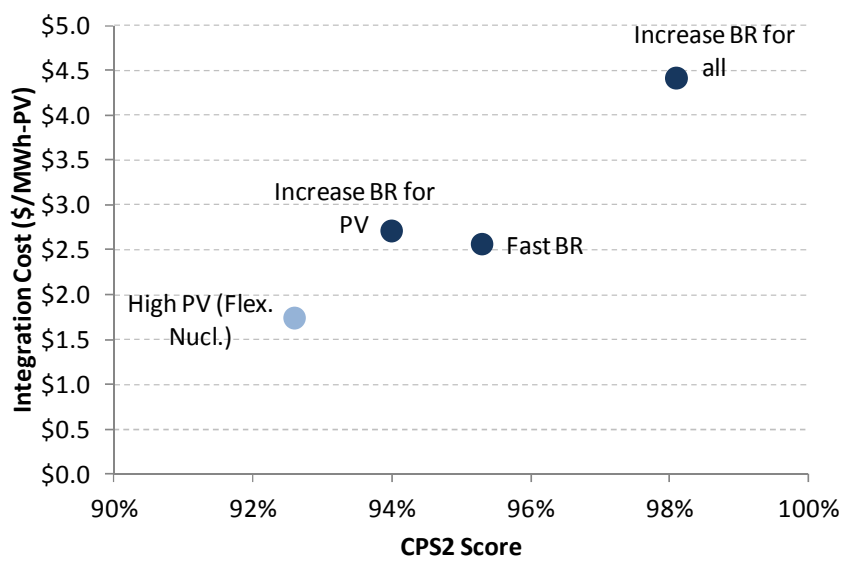

Fig. 5. Tradeoff between Balancing Performance (CPS2 Score for Net Load) and Integration Cost of PV 
Tables:

Table 1:

TABLE 1

\begin{tabular}{llcc} 
MAIN SCENARIOS USED TO EVALUATE THE IMPACTS OF PV (2027) \\
\hline Scenario & $\begin{array}{l}\text { Load } \\
\text { (peak } \\
\text { load) }\end{array}$ & $\begin{array}{c}\text { Wind } \\
\text { (nameplate cap) }\end{array}$ & $\begin{array}{c}\text { PV } \\
\text { (nameplate cap) }\end{array}$ \\
\hline Low PV & $9,151 \mathrm{MW}$ & $630 \mathrm{MW}$ & $1,674 \mathrm{MW}$ \\
High PV & $9,151 \mathrm{MW}$ & $630 \mathrm{MW}$ & $2,974 \mathrm{MW}$ \\
\hline
\end{tabular}

Table 2:

TABLE 2

NORMALIZED FoRECASTING ERROR STATISTICS FOR LOAD, WIND, AND SOLAR PV FOR DA (UPPER) AND HA (LOWER) (2027)

\begin{tabular}{cccccccc}
\hline \multicolumn{2}{c}{$\begin{array}{c}\text { Normalized Mean Absolute Error } \\
\text { (NMAE) }\end{array}$} & & \multicolumn{3}{c}{ Normalized Mean Square Error } \\
(NMSE)
\end{tabular}

Table 3:

TABLE 3

Generator CAPACITY AND Fuel PRice By TeChNOLOgy (ST-STEAm, CC-COMBined CyCle, CT-Combustion TuRbine)

\begin{tabular}{|l|c|c|c|c|c|}
\hline Technology & No. of Units & $\begin{array}{l}\text { Maximum } \\
\text { Capacity [MW] }\end{array}$ & $\begin{array}{l}\text { Minimum Capacity } \\
\text { [\% of max] }\end{array}$ & Total Capacity [MW] & $\begin{array}{l}\text { Fuel Price } \\
\text { [\$\$/MMBtu] }\end{array}$ \\
\hline Nuclear* (ST) & 3 & 387 & $100(50$ if flex.) & 1,162 & 0.50 \\
\hline Coal* (ST) & 8 & $108-488$ & $45-55$ & 1,982 & 1.96 \\
\hline Gas (ST) & 4 & $70-100$ & $25-48$ & 361 & 5.85 \\
\hline Gas (CC) & 9 & $88-672$ & $25-30$ & 3,206 & 5.85 \\
\hline Gas (CT) & 41 & $19-103$ & $25-50$ & 2,945 & 5.85 \\
\hline Oil (CT) & 2 & $16-54$ & 50 & 70 & 27.40 \\
\hline
\end{tabular}

* The 3 nuclear units and 5 coal units are partly owned and must-run.

Table 4:

TABLE 4

IMPACT OF PV IN 2027 USING BASE ASSUMPTIONS

\begin{tabular}{|c|c|c|c|c|}
\hline & No PV Case & \multicolumn{3}{|c|}{ PV Cases } \\
\hline & No PV (Const. Nucl.) & Low PV (Const. Nucl.) & High PV (Const. Nucl.) & High PV (Flex. Nucl.) \\
\hline $\begin{array}{l}\text { PV nameplate capacity } \\
\text { (MW-ac) }\end{array}$ & $0 \%$ & 1,674 & 2,974 & 2,974 \\
\hline $\begin{array}{c}\text { Energy from PV } \\
\text { (\% annual demand) }\end{array}$ & $0 \%$ & $8.8 \%$ & $14.3 \%$ & $16.8 \%$ \\
\hline $\begin{array}{l}\text { Renewable curtailment } \\
\text { (\% renewable energy) }\end{array}$ & $0 \%$ & $2.9 \%$ & $17.8 \%$ & $3.4 \%$ \\
\hline Maximum bal. reserve up (MW) & 187 & 278 & 556 & 556 \\
\hline $\begin{array}{l}\text { Average bal. reserve up } \\
\text { (MW) }\end{array}$ & 132 & 171 & 241 & 241 \\
\hline $\begin{array}{c}\text { CPS2 score } \\
\text { (must be }>90)\end{array}$ & 96.1 & 95.8 & 92.6 & 92.6 \\
\hline \multicolumn{5}{|l|}{ Integration Cost } \\
\hline Balancing reserve cost (\$/MWh-PV) & N/A & 1.61 & 3.56 & 1.11 \\
\hline DA forecast error cost (\$/MWh-PV) & N/A & 0.27 & 0.21 & 0.63 \\
\hline Total PV integration cost (\$/MWh-PV) & N/A & 1.88 & 3.77 & 1.74 \\
\hline
\end{tabular}


Table 5:

TABLE 5

OVERVIEW OF SENSITIVITY CASES FOR High-PV (FLEX. NUCl.) 2027 SCENARIO

\begin{tabular}{|c|c|c|}
\hline Category & Case & Description \\
\hline Benchmark & High-PV (Flex. Nucl.) & Base assumptions for high-PV (Flex. Nucl.) 2027 scenario \\
\hline \multirow{3}{*}{$\begin{array}{l}\text { Balancing reserves } \\
\text { (BR) }\end{array}$} & Increase BR for PV & $\begin{array}{l}\text { Use } 1 \text { st and 99th percentiles of deviations from PV HA schedules to set BR (but } \\
\text { continue to use } 2.5 \text { th to } 97.5 \text { th percentiles for load and wind deviations. }\end{array}$ \\
\hline & Increase BR for all & $\begin{array}{l}\text { Greatly increase BR for all by using } 0.1 \text { st and } 99.9 \text { st percentiles of deviations from PV, } \\
\text { wind, and load HA schedules to set BR rules. }\end{array}$ \\
\hline & Fast BR & $\begin{array}{l}\text { Require faster deployment rate of } \mathrm{BR}(5 \text {-min instead of } \\
10 \text {-min response time). }\end{array}$ \\
\hline \multirow{2}{*}{ Flexibility } & Low ramping & $\begin{array}{l}\text { Assume ramp rates for thermal generators are lower (use average ramp rates instead of } \\
\text { maximum block ramp rates). }\end{array}$ \\
\hline & $\begin{array}{l}\text { Minimum renewables } \\
\text { curtailment }\end{array}$ & $\begin{array}{l}\text { Minimize curtailment of renewable energy by adding a high curtailment penalty } \\
\qquad(\$ 10,000 / \mathrm{MWh})\end{array}$ \\
\hline \multirow[b]{2}{*}{ Fuel prices } & High gas price & Assume natural gas price increases by $25 \%$ from $\$ 5.85 / \mathrm{MMBtu}$ to $\$ 7.31 / \mathrm{MMBtu}$. \\
\hline & Low gas price & $\begin{array}{l}\text { Assume natural gas price decreases to } \$ 4.00 / \mathrm{MMBtu} \text { and coal price increases from } \\
\qquad \$ 1.96 / \mathrm{MMB} \text { tu to } \$ 3.00 / \mathrm{MMBtu} \text {. }\end{array}$ \\
\hline Forecasting & Perfect wind/load & Assume perfect DA and HA forecasts for wind power and load \\
\hline
\end{tabular}

